\title{
ELACIONES VISUALES ENTRE LA PRUDENCIA Y LAS VIRTUDES QUE LA COMPONEN
}

\author{
MARÍA MONTESINOS CASTAÑEDA** \\ Departament d'Història de l'Art. Universitat de València \\ Maria.Montesinos@uv.es
}

\begin{abstract}
Resumen: La Prudencia, como una de las Virtudes Cardinales, ha sido dividida por los pensadores en diferentes partes, las cuales exponen y especifican los objetivos y funciones de esta virtud. La imagen de la Prudencia se traduce en una alegoría portadora de diferentes atributos que constituyen la propia visualización de sus partes. Asimismo, muestra conexiones visuales con la imagen de la Prudencia.
\end{abstract}

Palabras clave: Prudencia / Iconografía / Virtudes Cardinales / Alegorías.

\section{VISUAL RELATIONS BETWEEN PRUDENCE AND THE VIRTUES THAT COMPOSE IT}

Abstract: Prudence, like one of the Cardinal Virtues, has been divided by the thinkers in different parts, which expose and specify the objective and functions of this virtue. Prudence's image is translated in an allegory that carries different attributes which constitute the own visualization of its parts. Likewise, the visualization of Prudence's parts shows visual connections with Prudence's image.

Key words: Prudence / Iconography / Cardinal Virtues / Allegories.

La Prudencia, como una de las Virtudes Cardinales ha sido definida, desarrollada y dividida por numerosos pensadores a lo largo de la historia. De entre las reflexiones sobre esta virtud podríamos distinguir dos tipos, por un lado, aquellas que atienden a su significado, definición y funciones; $y$, por otro, todas aquellas que versan sobre las subdivisiones de esta virtud en cuanto a las Virtudes que la componen.

\section{Las partes de la Prudencia}

Las Virtudes Cardinales se distinguen de las Teologales en que estas no tienen partes, como Dios, mientras que las Cardinales se componen de mu- chas partes, como el mismo hombre, del que se ocupan. ${ }^{1}$ Es evidente que la Prudencia tiene muchas partes, como consta por el hecho de que la mayoría de autores que han escrito sobre ella enumeran varias, aunque estos no coinciden en el número ni en el nombre. ${ }^{2}$ Aristóteles fue el primero en distinguir las subdivisiones que componen la Prudencia:

La memoria, la experiencia y la perspicacia son, cada una de ellas, o bien una consecuencia o una facultad concomitante con la sabiduría o prudencia. O bien se puede considerar que algunas de ellas son algo así como causas subsidiarias de la misma sabiduría, como, por ejemplo, la experiencia y la memoria, y otras como si fueran partes de la misma; por ejemplo, el deliberar bien y la perspicacia. ${ }^{3}$

\footnotetext{
* Fecha de recepción: 15 abril de 2019 / Fecha de aceptación: 2 de noviembre de 2019.

** Esta investigación se ha realizado gracias a la financiación de la Universitat de València y su programa de ayudas predoctorales "Atracció de Talent".

1 RAMÍREZ, Santiago; URDANOZ, Teófilo (eds.), 1960, p. 51.

2 RAMíREZ, Santiago; URDANOZ, Teófilo (eds.), 1960, p. 51.

3 ARISTÓTELES, De las Virtudes y los Vicios, 4, 1250 a 30-40 (1931, p. 257).
} 
De este modo, Aristóteles ya distingue cuatro partes de la Prudencia: Memoria, Experiencia, Perspicacia y Deliberación. No es de extrañar que Aristóteles considerara estas partes ya que definió a la Prudencia del siguiente modo:

Corresponde a la sabiduría o prudencia el deliberar, el juzgar los bienes y los males y todas aquellas cosas que en la vida hay que desear o hay que evitar, le corresponde el emplear dignamente todos los bienes disponibles, el conducirse de forma recta en sociedad, el prestar atención a las ocasiones debidas, el utilizar el lenguaje y la acción de una manera sagaz e inteligente, el tener un conocimiento hondo de todas las cosas que son útiles. ${ }^{4}$

No obstante, Cicerón destacó la capacidad electiva de la Prudencia como la principal de sus funciones: "de la primera, en que colocamos la prudencia y sabiduría, nace la indagación y descubrimiento de la verdad, y este es el oficio propio de esta virtud". ${ }^{5}$ Asimismo, basándose en las partes que Aristóteles había considerado, Cicerón enumeró tres:

La prudencia es el conocimiento de lo que está bien y lo que está mal y lo que no es ni una cosa ni otra. Sus partes son la memoria, la inteligencia y la previsión. La memoria es la facultad que permite al espíritu recordar los acontecimientos pasados; la inteligencia, lo que hace comprender los acontecimientos presentes; y la previsión, lo que permite adivinar las cosas antes de que sucedan. ${ }^{6}$

Como vemos, la implicación del aspecto temporal en la práctica de la Prudencia se manifiesta en sus partes (Previsión y Memoria), siendo necesarias para poder llevar a cabo la elección, es decir, la prin- cipal de sus funciones, como explica Séneca: "El sabio prudente y hábil, según las circunstancias, rechazará o escogerá cada cosa; pero ni teme lo que rechaza, ni ensalza lo que elige, supuesto que tiene un alma grande e invicta". ${ }^{7}$ Al ser la elección el principal aspecto que define a la Prudencia, Séneca lo menciona numerosas veces en sus obras: "Cuando alguien soporta los tormentos con entereza hace uso de todas las virtudes (...) allí está la Prudencia, sin la cual no se toma decisión alguna y nos persuade a soportar lo inevitable con la máxima entereza". ${ }^{8}$ Ante tantas consideraciones sobre esta virtud, Macrobio se basó en las partes ya establecidas para añadir otras tantas: "La prudencia comprende la razón, el intelecto, la cautela, la previsión, la facilidad de aprender, y la precaución". 9 Sin embargo, aunque Macrobio añadió más partes que sus antecesores, san Agustín de Hipona volvió a las partes que Cicerón ya había citado, manteniendo así tres: Memoria, Inteligencia y Providencia. ${ }^{10}$ San Agustín consideró estas partes atendiendo a que en la definición de la Prudencia destacó esta virtud por su conocimiento de la verdad $^{11}$ a través de la Elección ${ }^{12}$ y la Providencia ${ }^{13}$ que la caracterizan. San Isidoro (556-636) también destacó la importancia de la Providencia como parte de la Prudencia, explicando que el prudente es el que ve de lejos, es perspicaz y prevé con certeza a través de la incertidumbre de los sucesos. ${ }^{14}$ Más tarde, Alain de Lille mantuvo la Razón, la Providencia y la Precaución que Macrobio ya había considerado, añadiendo la Circunspección y la Docilidad a las partes de la Prudencia. Sin embargo, en su Tratado de las Virtudes destaca que normalmente los teólogos enumeran tan solo tres: la

${ }^{4}$ ARISTÓTELES, De las Virtudes y los Vicios, 4, 1250 a 30-40 (1931, p. 257). Aristóteles define la Prudencia en más partes de su obra, como por ejemplo: ARISTÓTELES, Ética nicomáquea, 6, 5, 1140a 25; 6, 12, 1144a 5 y 6, 5, 1140b, entre otras.

5 CICERÓN, Los oficios 1,5,15 (1946, p. 31).

${ }^{6}$ CICERÓN, La invención retórica, 2,53,160 (1997, p. 299).

7 SÉNECA, Epistolas Morales a Lucilio, 31,6 (2000, vol. 1, p. 229).

8 SÉNECA, Epístolas Morales a Lucilio, 67,10 (2000, vol. 1, p. 387).

${ }^{9}$ MACROBIO, Comentario al "Sueño de Escipión" de Cicerón, 1,8,7 (2006, p. 198).

10 Prudentia est rerum bonarum et malarum neutratumque scientia. Partes ejus, memoria, intelligentia, providentia. Memoria et per quam animus repetit illa quae fuerunt. Intelligentia, per qua mea perspicit quae sunt. Providentia, per quam futurum aliquid videtur antequam factum est. SAN AGUSTÍN, Octo quaestiones, 31.

11 Sed illud prudentia doctrinaque et desiderabam, et adhuc desidero, ni nota nobis facias ea ipsa ejus errata, quibus a fide veritatis ille virt tantus recessisse convicitur. SAN AGUSTín, Epistula 60,6,9; PL, 33, 157.

12 Per prudentiam boni malum scitur, elsi non sentitur. Tenetur enim bonum, ne amissione ejus sentitiatur malum. Item per experientiam mali scitur bonum; quoniam quid amiserit, sentit, cui de bono amisso male fuerit. SAN AGUSTín, De genesi ad litteram, 8,14,32; PL 34,385.

${ }^{13}$ Esto ergo alter Argus, imo illo cautior, illo studiosior, illo prudentior: ut sapias et intelligas, ac novissima prudenter provideas. SAN AGUSTín, Speculum, 4; PL, 40,987.

14 Prudens dicitur quasi porro videns, perspicax enim est, et incertorum videt casus. SAN ISIDORO, Orígenes, 1,10,201. 
Providencia, la Circunspección y la Precaución. ${ }^{15}$ Por otro lado, Hugo de San Víctor, tomando como referencia las reflexiones de los diferentes pensadores, hizo brotar de la rama de la Prudencia, del árbol de las Virtudes, ocho hojas correspondientes a las partes de esta virtud: Ratio, Consilium, Diligentia, Modestia, Memoria, Providentia, Timor Dei, Tolerantia. ${ }^{16}$ Por el contrario, Bono Giamboni, en II libro de' vizi e delle virtudi (s. XIII), redujo las partes a cinco, sin llegar a coincidir del todo con ningún autor precedente, sino combinando las distintas propuestas:

E passa questa virtú tutte l'altre, perché scevera l'uomodalle bestie per quelcotale conoscimento, ed è iguale cogli angioli. E conoscesi la buona dalla ria per cingue cagioni, ed ha catuna il suo nome per commendalle meglio amemoria. E la nomora di quelle vie sono le virtú che nascono di Prudenzia, e sono cosí appellate: Buona memoria, Buono conoscimento, Buono provedimento, Buono esaminamento, Buona elezione. ${ }^{17}$

Sin embargo, fue santo Tomás de Aquino quien desarrolló una clasificación completa de las partes de la Prudencia atendiendo a las funciones y naturaleza de las mismas. ${ }^{18}$ Santo Tomás atribuye a la Prudencia las seis partes que le asignaba Macrobio, más la "memoria" que aportaba Cicerón, y la "sagacidad" que añadía Aristóteles, explicándolo así: "De estas ocho, cinco pertenecen a la prudencia como cognoscitiva: la memoria, habilidad en el raciocinio, inteligencia, docilidad y sagacidad; y tres a la prudencia como preceptiva, a saber: la previsión o providencia, la circunspección y la precaución". 19

No obstante, en los siglos siguientes las partes de la Prudencia continuaron variando dependiendo del pensador que las citara, sin coincidir en número ni en nombre. En el capítulo XVIII -de la Pru- dencia- de Flor de Virtudes (1313-1323), fray Tommaso, basándose en Cicerón, citó como partes de la Prudencia tan solo tres (Memoria, Inteligencia y Providencia), aunque hace referencia a cuatro más (Discernimiento, Razón, Consejo y Diligencia):

Según Tulio tiene tres virtudes: la primera es haver recuerdo e memoria de las cosas pasadas; la segunda es inteligencia de discernir las cosas que ha de fazer conviene saber, el bien del mal e la verdad de la falsía, e ordenar sus cosas por forma de razón; la tercera es providencia, conviene saber proveer ante del tiempo a los negocios. / E estas tres virtudes se informan por dos otras maneras, que son consejo e diligencia. ${ }^{20}$

También siguió a Cicerón Michael de Praga, ya que en su De regimine principum (1387) tan solo cita como partes de la Prudencia tres: Memoria, Inteligencia y Providencia. Sin embargo, aunque no siempre sean exactamente las mismas suelen ser semejantes o sinónimas. Francisco de Imperial en El dezir de las syete virtudes (ca. 1407) presentó la imagen literaria de la Prudencia aludiendo así mismo a sus partes: "Mira Prudençia commo faz loçanas / sus anbas fazes mirando el espejo, / e de una en una mira sus hermanas, (...) Providençia, Conprehender, Enseñamiento, / Cautela, Soliçidat, Acatamiento; / éstas sson fijas, en obras non son vanas". ${ }^{21}$ Igualmente, Dom Duarte, basándose en Aristóteles, ${ }^{22}$ incluye como aquello que es necesario para alcanzar la Prudencia: "poseer capacidad para recordar, es decir Memoria; ser avisado, previendo lo que ha de acontecer, Providencia; contar con buenos consejeros, Consejo; y la sabiduría". ${ }^{23}$ Por su parte, Juan de Mena no citó las partes de esta virtud directamente, aunque al definirla mencionó algunas de ellas: "Mas tan larga, que mostraua / su hedad y sapiencia, / ser digna de reuerencia / la obra, no lo ne-

\footnotetext{
15 Delhaye considera que son las mismas partes que Cicerón había tratado pero adaptadas a la teología. Vid. DELHAYE, Philippe, 1963, p. 15.

16 HUGO DE SAN VÍCTOR, Summa Sententiarum, 3; PL 176,114.

17 GIAMBONI, Bono, 1968, p. 5.

18 Las partes en cuanto a la virtud a la que se refieren son correlativas al todo, pero hay tres tipos de todos: uno esencial o universal; otro cuantitativo o integral; y otro virtual o potencial. Concretamente, la Prudencia tiene partes esenciales y potenciales. Por lo que respecta a las integrales, son en sentido impropio, ya que se refieren a sus oficios y funciones, pues todas ellas colaboran de una manera o de otra al acto perfecto de la Prudencia, como todas las partes integrales de un compuesto corporal concurren de algún modo a la constitución del todo. Vid. RAMíREZ, Santiago; URDANOZ, Teófilo (eds.), 1960, pp. 51-52.

19 Más allá de la tradición filosófica establecida en cuanto a las partes de la Prudencia, Santo Tomás hizo distinción entre la Prudencia personal, la familiar, la gubernativa, la cívica, la militar, la sensatez y la resolución equitativa. La Prudencia gubernativa y militar se visualizan en la imagen de la Prudencia mediante atributos como el yelmo, la armadura o el cetro.

20 MATEO PALACIOS, Ana, 2013, p. 67.

21 IMPERIAL, Francisco de, 1977, pp. 107-112.

22 CARVALHO, Armando Luís, 2007, p. 940.

23 DUARTE, Dom, 1998, pp. 209-211.
} 
gaua; / lo pasado memoraua / ordenando lo presente, / proueyendo sabiamente / lo que por venir estaua. (...) Aconseja que la razón se siga y no la voluntad (...) Da consejo". ${ }^{24}$ No fue el caso, de Francisco de Guzmán, quien en sus Triumphos morales sí explicó claramente qué partes considera que forman a la Prudencia:

De muchas grandes partes fue prudencia / compuesta, por las quales es guiada, / y aquella que le da mayor potencia / memoria por vosotros es llamada. / Y en ella toma fuerças experiencia / que poco menos debe ser preciada, / industria, buen consejo que diremos / y mas si mas lugar después tenemos. ${ }^{25}$

A pesar de que los diferentes autores no coinciden del todo en el número ni denominación de las partes, todos concuerdan en que estas partes son características propias de la Prudencia, designando así las funciones que la virtud ha de desempeñar. Estas reflexiones teóricas tuvieron correspondencias visuales en la imagen de la Prudencia, siendo sus atributos y características visuales manifestaciones de las partes que conforman a esta virtud. ${ }^{26}$ Durante la Edad Media, como las Virtudes no estaban organizadas ni en número ni en nombre, en muchos casos, tanto la Prudencia como las otras Virtudes Cardinales, se representaban mediante alguna/s de sus partes. Ya en la Edad Moderna, tras la sistematización teórica y visual de las Virtudes Cardinales, cada una de ellas se representó rodeada de las personificaciones de sus partes. Todo ello derivó en la personificación individualizada de las partes, lo que muestra diversas correspondencias visuales con la virtud a la que pertenecen, como veremos en "La Prudencia y sus partes".

\section{Visualización de la Prudencia junto a sus partes}

Como se ha visto en el preámbulo del presente capítulo, la Prudencia consta de muchas partes o sub- subdivisiones que los pensadores le han adjudicado a lo largo de la historia. En el Hortus deliciarum (s. XIII) la Prudencia ya aparece acompañada por el Temor de Dios, el Consejo, la Memoria, la Inteligencia, la Providencia, la Deliberación y la Razón. ${ }^{27}$ Más tarde, los árboles de Virtudes, como el de Hugo de San Víctor en De fructibus carnis et spiritus (Studienbibliothek, Salzburg, M.S. Sign. V. I. H. 162, fol. 76r.), representaron las partes de la Prudencia en forma de hojas en las que se inscribían sus nombres. ${ }^{28}$ Dicha tradición del árbol de las Virtudes en el que se clasifican con sus respectivas partes se mantiene hasta el siglo XVII, como vemos en el del Cursus Theologicus, donde la Prudencia se considera virtud intelectual y está separada de las otras Virtudes Cardinales. En este caso, las subdivisiones de la Prudencia corresponden a los tipos de partes que la componen, reflejando el pensamiento de Santo Tomás y otros pensadores que profundizaron más en la cuestión. ${ }^{29}$ Volviendo al medievo, en el Breviloquium de virtutibus, John of Wales (finales del s. XIII) dedicó un capítulo a cada una de las partes que Cicerón le había designado a la Prudencia: Memoria, Inteligencia y Providencia. Sin embargo, en el sexto capítulo de esta otra, añade las partes de Macrobio: Razón, Intelecto, Ciscunspección, Providencia, Docilidad y Precaución. ${ }^{30}$ Ya en el Miroir du monde (1373) la Prudencia se representa portando un libro abierto que lee a sus damas, quienes están sentadas a sus pies. ${ }^{31}$ Esta imagen se repite en uno de los manuscritos más famosos de la Ética de Aristóteles (s. XIV, Rouen, BM, ms. 927, fol. 93v), en el que, además, las damas que acompañan a la Prudencia llevan filacterias que las identifican como sus partes: Circunspección, la Providencia, la Precaución y la Docilidad. Por otro lado, las partes que John of Wales había designado a la Prudencia se representan como damas que la acompañan en una miniatura del Livres des quatre vertus (Cristina de Pizán, 1405,

\footnotetext{
24 MENA, Juan de, 1912, pp. 146-147.

25 GUZMÁN, Francisco de, 1565, fol. 70r.

26 Los atributos que acompañan a la Prudencia son manifestaciones visuales de sus partes, estableciendo las siguientes correspondencias: libro-Conocimiento, serpiente-Cautela/Precaución, espejo-Circunspección y Docilidad, objeto lumínico (antorcha o lámpara)-Intelecto, ataúd o calavera-Precaución/cautela, criba-Deliberación y Elección, bolsa de monedas-Circunspección, aspecto bifaz o trifaz-Memoria, Inteligencia y Providencia/Previsión.

27 McGUIRE, Thérèse B., 1990, p. 192.

28 Consilium, Timor domini, Memoria, Intelligentia, Providentia, Rationabilitas, Sagacitas.

${ }^{29}$ La Prudencia se divide en tres partes: Eubulia (la virtud del buen consejo), Gnome (habilidad de juzgar correctamente cosas extraordinarias) y Synesis (la virtud del sentido común en asuntos prácticos); mientras que las especies de la Prudencia son: Oeconomica, Regnativa, Democratica, Monarchica, Aristocratica, Consilii (el don del Consejo), Misericordes, Militaris, Politica, Monastica, Discretio spirituum (discernimiento de los espíritus). Vid. FLORIANI, Peter J., 2014, pp. 43-44.

30 TUVE, Rosemund, 1963, p. 270.

31 MÂLE, Emile, 1951, p. 310.
} 
Oxford, Bli, ms. Laud Misc. 570), donde se identifican como: Razón, Inteligencia, Circunspección, Docilidad, Providencia y Precaución. No obstante, aunque la Prudencia se representa junto a sus partes, personificadas como damas, estas solo se identifican por filacterias ya que no llevan ningún atributo, para lo que habrá que esperar hasta el siglo XVI. El segundo panel de la serie Los Honores (Pieter van Aelst, 1517-1525) está dedicado a la Prudencia, quien aparece entronizada conversando con la Fe y la Razón, quien muestra a la Prudencia un triple espejo como emblema de la Memoria, Inteligencia y la Providencia. A los pies del trono se sitúan siete mujeres que representan las siete partes que componen a la Prudencia: la Inteligencia portando un fuelle; la Cautela con un espejo en el que se mira un zorro; la Circunspección con una bolsa de dinero y compás; el Intelecto con un caduceo y un libro; la Providencia, ataviada de armadura y lanza, lleva un globo terráqueo y un búho sobre la cabeza; la Docilidad sostiene un libro y un manojo de varas; $y$, la Memoria lleva un corazón, órgano que digiere las experiencias pasadas. Además, el tapiz se completa con las Artes Liberales, los cinco sentidos, escenas bíblicas y personajes representativos de la Prudencia. Todo el conjunto de figuras se acompaña de una serie de cartelas que explican las imágenes, queriendo ilustrar el tapiz cómo la Sabiduría ayuda al gobernante a ver la Verdad sobre la inconstante Fortuna, ${ }^{32}$ para lo que necesita la Prudencia en su totalidad. ${ }^{33}$ Sin embargo, no siempre las figuras alegóricas que acompañan a la Prudencia son sus partes, como vemos en La Prudencia de Luca Giordano (1682-1683, Florencia, Palazzo Medici-Ricardi), donde sobre dicha virtud se sitúan la Gracia, el Bienestar y la Abundancia, así como a su izquierda aparecen dos filósofos que representan el Orden y la Razón. Sin embargo, lo más interesante no es la representación de la Prudencia junto a sus partes, sino la personificación de estas últimas en relación con la virtud a la que pertenecen, es decir, la interacción visual entre ambas. De este modo, las partes suelen presentar correspondencias visuales con la Prudencia mediante los atributos que porta. No obstante, esto no ocurre con todas las personificaciones de sus partes, ${ }^{34}$ por lo que solo se atenderá a aquellas que presentan interacción visual con la Prudencia. ${ }^{35}$

\section{Relación visual entre la Prudencia y sus partes}

La correspondencia visual más acusada de la Prudencia ${ }^{36}$ con sus partes es con aquellas que representan su relación con los estados de tiempo: Memoria y Previsión/Providencia. Por este motivo, santo Tomás explicó: "Conviene que de las cosas pasadas saquemos como argumentos para hechos futuros. Por eso mismo, la memoria de lo pasado es necesaria para aconsejar bien en el futuro". ${ }^{37}$ Bono Giamboni en Il libro de' vizi e delle virtudi (s. XIII) consideró la Memoria como la primera de las Virtudes de la Prudencia por la importancia del tiempo en la reflexión de esta virtud:

Per Buona memoria, ch'èlaprima virtù di Prudenzia, si conosce la buona cosa dalla rea in questo modo. Tu hai a fare una cosa: puoi prendere molte vie, e dubiti qual è buona e quale è migliore delle buone, o delle ree qual e la meno rea; e per te bene conoscere no.llo sai. Ricorri a questa virtú ch'è detta Buona memoria, e ricorditi d'alcuno fatto passato che tu abbi veduto o udito ad altrui dire, che sia come questo fatto, overo a questo simigliante, chai tra le mani a diliberare, e vedi che via vi s'è tenuto, se n'è capitato bene o male. Se n'è bene capitato, tiene quella via; se n'è capitato male, guàrdati di tenere quella via. ${ }^{38}$

Una de las representaciones más antiguas del doble rostro es la que se encuentra en Le pelerinage de vie humaine (s. XIV) de Guillaume de Digulle-

\footnotetext{
32 TUCKER, Shawn R., 2015, p. 195.

33 MONTESINOS, María, 2015, pp. 113-120.

${ }^{34}$ La suma de las propuestas de partes en las que se subdivide la Prudencia según los diferentes autores es: Memoria, Previsión/Providencia, Consejo, Deliberación, Elección, Razón, Conocimiento, Inteligencia, Intelecto, Entendimiento, Docilidad, Experiencia, Cautela, Precaución, Circunspección, Sagacidad y Temor de Dios.

${ }^{35}$ Cada parte será tratada brevemente en cuanto a su concepción filosófica, atendiendo sobre todo a su relación con la Prudencia. Respecto a la visualización de las partes, nos centraremos en su visualización durante la Edad Moderna, periodo de máxima profusión alegórica, así como en los tipos iconográficos que presentan relación visual con la Prudencia. Cabe tener en cuenta que un estudio más profundo de la visualidad de cada parte sería objeto de una investigación más amplia y específica sobre estas.

${ }^{36}$ Para comprender las relaciones visuales existentes entre la Prudencia y sus partes es conveniente conocer previamente la visualización de esta virtud, ya estudiada anteriormente. MONTESINOS, María, 2014, pp. 97-114.

37 SANTO TOMÁS, Summa Theologica, [41069] II-llae q. 49 a. 1 ad 3 (1960, p. 60).

38 GIAMBONI, Bono, 1968, p. 5.
} 


\section{MUEMOIR}

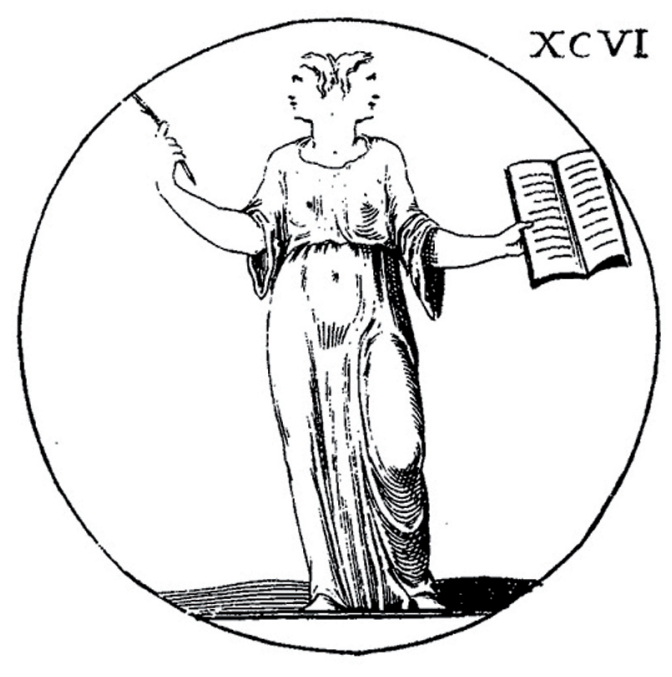

Fig. 1. Memoria, Iconología, Cesare Ripa, 1643, París.

ville, donde encontramos una miniatura que representa a la Memoria con aspecto bifaz pero con la peculiaridad de que solo tiene ojos en la cara que mira hacia el pasado, el rostro propio de la Memoria. ${ }^{39}$ La Memoria de Digulleville es la depositaria de las Virtudes que la gracia de Dios ha conferido al alma, de manera que es ella la que garantiza la salvación del alma humana. ${ }^{40}$ Siglos después, Cesare Ripa concibió la imagen de la Memoria [Fig. 1] con el mismo aspecto bifaz que el medievo le había concedido, pero esta vez con ojos en ambas caras:
Es la memoria un don particular que por naturaleza se tiene, siendo de la mayor importancia y consideración, pues gracias a ella puede abarcarse y recordarse la totalidad de lo pasado; con lo cual, en virtud de dicho conocimiento, nos podemos regular con la Prudencia, previendo y calculando por lo ya sucedido las cosas por venir, por cuya causa además se le pintan dos caras. ${ }^{41}$

En la imagen de la Prudencia, la cara que mira hacia el pasado -generalmente con aspecto anciano- es el rostro de la Memoria, con el fin incorporar los recuerdos al presente. ${ }^{42}$ Esto ocurre tanto con el aspecto bifaz como con el trifaz, pues en ambos casos una de las caras mira hacia el pasado. Mediante estas asociaciones, la Prudencia se entiende como el acto por el cual el sujeto se mueve por propia iniciativa ante una situación dada enfrentándose a la adversidad ayudándose de la Memoria y la Providencia o Previsión. ${ }^{43}$ Además de esta peculiaridad, la Memoria también comparte con la Prudencia el libro como atributo: "en cuanto al libro y la pluma, muestran y significan, según suele decirse, que la memoria se perfecciona con el uso, consistiendo dicho uso especialmente en leer o escribir con la mayor frecuencia que se pueda". ${ }^{44}$ También Boudard concibió la Memoria escribiendo un libro, mientras que Gaucher situó unos libros a sus pies además de otras características que ofrecen una completa alegoría de esta virtud. ${ }^{45}$ Conjuntamente a los libros, la Memoria se acompaña de un perro, ${ }^{46}$ de una tabla en la que se representan los cinco sentidos ${ }^{47}$ y de unas musas consideradas sus hijas. ${ }^{48}$ Con esto, se explica la importancia de la experiencia y los sentidos en el uso de la Memoria, mediante la cual se crean los recuerdos. Para configurar la Memoria es necesaria la Experiencia, otro los aspectos importantes de

39 AMBLARD, Paule, 1998, pp. 68-71.

40 VIVES-FERRÁNDIZ, Luis, 2011, p. 119.

41 RIPA, Cesare, 2007, vol. 2, p. 67.

42 MONTESINOS, María, 2017, pp. 505-516.

43 MAUPEU, Philippe, 2012, p. 45.

44 RIPA, Cesare, 2007, vol. 2, p. 67.

45 Ornement de l'esprit, la Mémoire est représentée jeune, parce que c'est le temps le plus propre à cette faculté de l'ame. C'est dans le cerveau que se gravent les conceptions, et c'est pour exprimer cette pensé qu'on a fait tenir un burin à la Mémoire. GAUCHER, Charles-Etienne; GRAVELOT, Hubert F.; COCHIN, Charles N., 1791, vol. 3, p. 63.

46 Le chien placé près d'elle signifie qu'en général les animaux, et particulièrement le chien, jouissent de cette faculté". GAUCHER, Charles-Etienne; GRAVELOT, Hubert F.; COCHIN, Charles N., 1791, vol. 3, p. 63.

47 Comme les idées nous sont communiquées par les sens, ce sont eux que désignent naturellement les cinq figures tracées dans le tableau sur lequel s'appuie la Mémoire. GAUCHER, Charles-Etienne; GRAVELOT, Hubert F.; COCHIN, Charles N., 1791, vol. 3, p. 63.

48 les objets du fond, analogues à la figure, laissent voir les muses, appellées les filles de mémoire, parce que ce sont elles qui consacrent les faits dignes d'être conservés dans le temple du même nom. GAUCHER, Charles-Etienne; GRAVELOT, Hubert F.; COCHIN, Charles N., 1791, vol. 3, p. 63. 
la virtud que nos ocupa. Este aspecto ya lo había considerado Aristóteles siglos atrás, lo que Gracián recoge y recuerda en el aforismo 60: "Buen juicio (...). Con la edad y la experiencia la razón madura completamente". ${ }^{49}$ Al respecto, en la empresa Fulcitur experientiis [Está sustentado en las experiencias], Saavedra pone en relación directa la necesidad de la Experiencia en la Prudencia: "la experiencia, madre de la prudencia, con quien se afirma la sabiduría (...) que es hábito de la razón, con el conocimiento de lo bueno o lo malo, y con el uso y exercicio". ${ }^{50}$ Por estos motivos, en referencia a la razón y el conocimiento, Gaucher visualizó la Experiencia rodeada de libros, imagen que un siglo después Pastor recogió en su Iconología. ${ }^{51}$

Por otra parte, Saavedra, siguiendo a los clásicos, consideró las partes de la Prudencia en relación con la importancia del tiempo en su ejercicio: "Consta esta virtud de la prudencia de muchas partes, las cuales se reducen a tres: memoria de lo pasado, inteligencia de lo presente y providencia de lo futuro".52 Pues, así como la parte trasera del aspecto bifaz de la Prudencia hace referencia al pasado y, por lo tanto, a la Memoria, la parte delantera representa el futuro y la Providencia. Aristóteles consideró característica de la Prudencia este aspecto: "Se llama prudente el que puede examinar bien todo lo que se refiere a sí mismo y eso es lo que se confiará a la Prudencia. Por eso también se dice que son prudentes algunos animales, aquellos que parecen tener cierta facultad de previsión para su propia vida". ${ }^{53}$ Esta consideración fue recogida por los pensadores, por lo que la mayoría de ellos consideraron la Providencia ${ }^{54}$ como una de las partes de la Prudencia, como hizo Daude de Pradas:

Cil davant anom providenza, / o savieza, o prudença (...) Providenza vol dire tan / com far luyn esgardar avan. / Providenza fay loyn gardar / ab uells de cor ço c'om deu far. I Aisso eis dizon l'autre nom, / qui bels enten de cap e som. I Davan estai cesta vertutz I si com ferm e feels escutz; / e cel qui la vol e la te / cosseil ades per bona fe..$^{55}$

También Bono Giamboni consideró la Providencia como una de las partes de la Prudencia, definiéndola del siguiente modo:

Per Buono provedimento la buona cosa si conosce dalla rea e fassi il meglio delle cose, quando l'uomo pensa e vede della cosa c'ha a fare che ne può per inanzi incontrare od avenire, o che uscita I[a cosa] puote avere. Perché l'uscita è fine delle cose, dando della cosa perfetta verace conoscimento. ${ }^{56}$

Igualmente, Geoffrey Chaucer (ca. 1343-1400), en el Cuento de Melibeo ${ }^{57}$ (la segunda historia de los Cuentos de Canterbury,1387-1400), presenta como esposa de Melibeo a Prudencia, cuyo nombre proporciona la clave de toda la historia. Este personaje actúa siempre prudentemente en su acción, así como anticipa los acontecimientos futuros para que tengan un buen final: Thanne dame Prudence, when she saw the goodwill of her husband, deliberatede and took advice of herself how she might bring this whole matter to a good end. ${ }^{58}$ Por consiguiente, tanto en el ámbito filosófico, como el literario y visual la Providencia se asocia a la Prudencia como una de sus partes. Más tarde, Ripa recogió la tradición visual de la Provi-

49 GRACIÁN, Baltasar, 1994, p. 35.

50 SAAVEDRA FAJARDO, Diego de, 1675, p. 182.

51 GAUCHER, Charles-Etienne; GRAVELOT, Hubert F.; COCHIN, Charles N., 1791, vol. 2, p. 33. Un siglo después Pastor recogió en su Iconología la mima tanto la misma imagen de la Experiencia como el mismo texto, aunque esta vez traducido al casteIlano: "Hija del tiempo y de la reflexión, la Esperiencia se representa por una mujer de edad ya avanzada, en actitud grave, teniendo en la mano izquierda el cuadrado geométrico, y en la derecha una varilla rodeada de esta inscripción; Berum Magistral Maestra de las cosas. Sabido es que el cuadrado geométrico, dividido en grados, da, por medio de la multiplicación de sus dos números, las proporciones, las relaciones y las distancias. Instruida por los sentidos, la Esperiencia tiene derecho de arreglarlos y de rectificarlos; y por esto se la representa teniendo la varilla en señal de mando, debiendo presidir la Experiencia, no solo las ciencias y las artes, sino todos los conocimientos humanos". PASTOR, Luis G., 1866, p. 145.

52 SAAVEDRA FAJARDO, Diego de, 1675, p. 172.

53 ARISTÓTELES, Ética nicomáquea, VI, 7, 1141a 25 (1985, p. 276).

La presencia de animales como atributos o emblemas de la Prudencia, al igual que de las otras Virtudes, se explica mediante la asociación de un comportamiento de dicho animal que es propio de la virtud a la que representa.

${ }^{54}$ Los términos "providencia" y "previsión" han sido utilizados indistintamente por los autores para hacer referencia al mismo concepto por lo que nos referiremos a esta parte con ambos términos, atendiendo a la elección del autor.

55 PRADAS, Daude de, 1879, p. 25 (vv. 205-222).

56 GIAMBONI, Bono, 1968, p. 6.

57 CHAUCER, Geoffrey, 1934, pp. 189-236.

58 CHAUCER, Geoffrey, 1934, p. 230. 


\section{PREVOYANCE.}

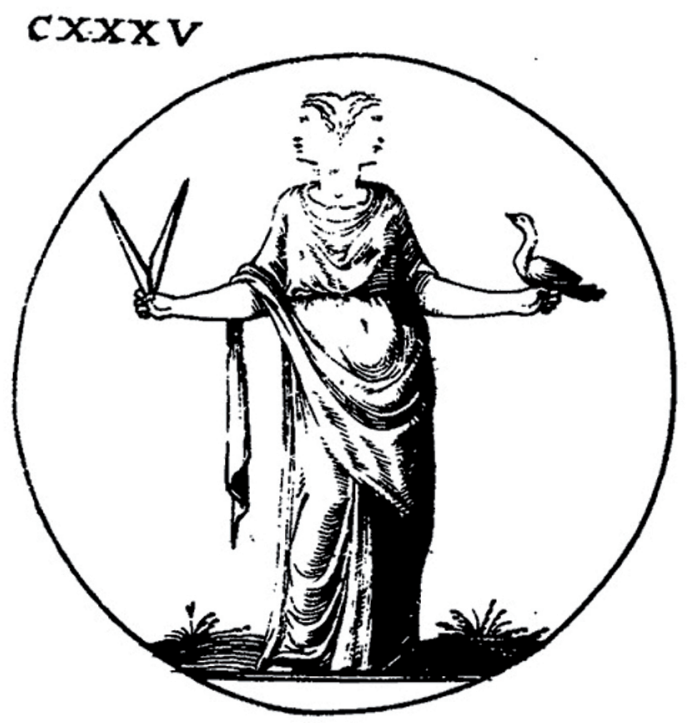

Fig. 2. Previsión, Iconología, Cesare Ripa, 1643, París.

dencia ${ }^{59}$ para plasmarla en su propia alegoría de la Previsión, caracterizada por la multiplicidad de rostros [Fig. 2]: "Mujer con dos cabezas que ha de ir vestida de amarillo, cogiendo un Schirato con la diestra y compás con la siniestra" ${ }^{60}$ Además, Ripa relaciona directamente las dos cabezas con la Prudencia:

Las dos cabezas muestran que a fin de que preveamos las cosas por venir, será de gran ayuda el mejor conocimiento de las cosas pasadas; pues es sabido que la experiencia viene a ser causa y razón de la Prudencia de los hombres, siéndole facilísimo ejercer la Previsión al que es prudente y siendo además el prever y el proveer efectos propios de la virtud de la Prudencia. ${ }^{61}$

Por este motivo, Ripa no olvida mencionar la relación de dicha fisionomía con la del dios Jano ${ }^{62}$, así como la posesión del gobernante de dicha virtud $^{63}$ asociación que ya había sido establecida por Macrobio siglos atrás:

Después, el gobierno recayó sólo en Jano, quien se cree que tuvo dos caras, de tal manera que contemplaba lo que había delante y lo que había detrás de su espalda; esto, sin duda, hizo referencia a la Prudencia y talento del rey, quien no sólo había conocido lo pasado sino que había anticipado el futuro. ${ }^{64}$

Por otro lado, como vemos en la descripción, la Previsión también comparte el compás con la Prudencia, ${ }^{65}$ al igual que la Parsimonia y la Ciencia, del que explica: "se muestra claramente que para prever las cosas se deberán medir con gran cuidado las cualidades, órdenes, disposiciones, tiempos y accidentes, con el auxilio y ayuda del más sabio juicio y de los más discretos pensamientos". ${ }^{66} \mathrm{Gau}$ cher, recoge tanto el aspecto bifaz de la Previsión como el compás como atributo explicando al respecto:

Prudencia activa que dan la esperiencia y el juicio. Los antiguos pintaban la Prevision con doble cara, para denotar que el conocimiento del pasado sirve para preveer los acontecimientos futuros; pero desde que el buen gusto ha desterrado de la alegoría estas monstruosidades repugnantes, se representa la Previsión bajo la forma de una mujer de edad avanzada, con la vista'atenta y en actitud de marchar: en una mano tiene un compás abierto, emblema de la

59 Vid. HOURIHANE, Colum, 2000, p. 278.

60 RIPA, Cesare, 2007, vol. 2, p. 225. Aunque Ripa describe que sostiene al schirato con la derecha y el compás con la izquier$\mathrm{da}$, en el grabado encontramos dichos elementos invertidos. En cuanto al término schirato, puede traducirse como "ardilla", a pesar de que el animal representado en el grabado se asemeja más a un pájaro.

61 RIPA, Cesare, 2007, vol. 2, p. 225.

62 Además de Jano, el aspecto bifaz o trifaz que adquieren tanto la Previsión como la Prudencia fue asociado al dios Serapis, quien suele ir acompañado por un monstruo de tres cabezas que hace alusión a los tres estados del tiempo. Vid. CARTARI, Vicenzo, 1581, p. 55. No obstante, no fue Cartari el único que puso en relación al dios egipcio con el aspecto trifaz, pues encontramos amplia presencia de dicha asociación en el ámbito emblemático. Vid. SENÉS, Gema, 2011, pp. 759-772.

63 "Entre las gentes plebeyas es creencia común que la Previsión o Providencia nos viene directamente de los Príncipes, siendo así que a los Príncipes les proviene de Dios, dador universal de todo bien". RIPA, Cesare, 2007, vol. 2, p. 227.

${ }^{64}$ MACROBIO, Saturnales, 1, 7, 20 (2009, p. 112).

${ }^{65}$ Cuando la Prudencia lleva como atributo algún instrumento de medida (compás, vara, reloj, escuadra, esfera armilar, etc.) hace alusión a la buena medida que caracteriza a esta virtud. Además, la noción de mesura que debe caracterizarla pone de manifiesto la dependencia teórica y visual de las Virtudes Cardinales ya que la mesura es el principal rasgo de la Templanza.

${ }^{66}$ RIPA, Cesare, 2007, vol. 2, p. 225. 
rectitud, y en la otra una varilla con un ojo en la estremidad superior, rodeado de rayos; tales son los símbolos conocidos de la previsión y de la vigilancia, de que ha hecho uso Mr. Mignard para pintar la Previsión en la galería de Versailles. ${ }^{67}$

Este ojo coronado de rayos lo encontramos en la alegoría de la Providencia (o Previsión) que concibió Boudard (1759), la cual, en lugar de tener aspecto bifaz, tiene un sol en el pecho en cuyo centro alberga un ojo. ${ }^{68}$ Por otro lado, Ripa, también incluye en la segunda alegoría de la Providencia el aspecto bifaz, al que añade otros atributos en relación con la Prudencia como son la vid y el timón. En cuanto la vid, hace referencia a la Prudencia en su vertiente temperada, queriendo significar que se ha de ser prudente en el beber, siendo necesario prever las consecuencias que tendría lo contrario. Respecto al timón, aunque es un atributo poco habitual en la imagen de la Prudencia, suele hacer referencia a ella en el ámbito emblemático en cuanto a su oposición a la Fortuna, cosa que Ripa también manifiesta:

Con el timón se nos muestra además de esto que también en los Mares es preciso emplear la previsión en numerosas ocasiones, alcanzándose de este modo la fama y las riquezas, y aun muy a menudo salvar la propia vida. Así la Previsión sujeta y endereza el timón que nos guía, proporcionando a nuestras vidas la esperanza, siendo dicho timón que rige nuestras personas, como la nave en alta mar, levantado y sacudido por todas partes por los vientos de Fortuna. ${ }^{69}$

Igualmente, Ripa apunta que en una medalla de Tito también aparecía un timón en alusión a la Providencia. ${ }^{70}$ También Mendo, bajo el lema Firmis haerendum [Hay que ser firme en las resoluciones] representa un timón en alusión a la Previsión y la Prudencia: "y consejos firmes, que son sus ancoras, sondando de antemano despacio, y con prudencia la altura, y fondo de las dificultades, conveniencias, y daños". ${ }^{71}$

Aunque de diferente modo, el Buen Consejo también se representa portando tres cabezas. A pesar de que el Consejo es uno de los dones del Espíritu Santo, como bien enumera Isaías (Is 11,2), los pensadores lo consideraron propio de la Prudencia y las funciones que esta virtud implica: "siendo propio de la prudencia emitir los actos de consejo, deliberación o consejo, juicio e imperio respecto de los medios con los que se llega al fin debido". ${ }^{72}$ Santo Tomás consideró el Consejo como parte potencial de la Prudencia, distinguiéndola de la mayoría de sus partes, consideradas integrales. Igualmente, en el capítulo XVIII de Flor de Virtudes (1313-1323) -dedicado a la Prudencia-, encontramos referencia a las fuentes bíblicas como origen de la consideración del Buen Consejo como parte de esta virtud: "Salomón dize: 'Faz tus cosas con buen consejo e no te reprentirás'" ${ }^{73}$ Por su lado, Daude de Pradas además de definir el Buen Consejo, ${ }^{74}$ lo identificó con el espejo, atributo propio de la Prudencia: Moures deu hom per bon conseil, I car bon conseil sembla espeil; / si com cel qu'en l'espeil se mira, / sa faizo garda e cossira, / si ren i poiria genzar, / si deu hom en consseill mirar. ${ }^{75} \mathrm{Sin}$ embargo, Ripa no recoge este atributo en la alegoría del Buen Consejo, aunque sí expone otros relacionados con la Prudencia:

Anciano revestido con largos ropajes de color rojo. Lleva una cadena de oro de la que cuelga un corazón y aparece sosteniendo con la diestra un libro cerrado, viéndose sobre él una lechuza, mientras con la izquierda sujeta tres cabezas, tomándolas por el cuello. De éstas, una será de perro -la que mira hacia la derecha, otra de lobo -la que mira hacia la izquierda-y la última, que va en medio, de león. ${ }^{76}$

67 PASTOR, Luis G., 1866, pp. 146-148. GAUCHER, Charles-Etienne; GRAVELOT, Hubert F.; COCHIN, Charles N., 1791, vol. 2, p. 33.

${ }^{68}$ C'est-à-dire la sagesse \& la puissance divine qui gouverne tout. / On la personnifie par une Matrône vêtu majestueusement \& portée sur un nuage, tenant un grand base dont elle répand la rosée sur un globe terrestre. Elle a un oeil ouvert \& rayonnant sur sa poitrine, pour marquer que rien ne lui est caché. BOUDARD, Jean Baptiste, 1759, vol. 3, p. 83.

${ }^{69}$ RIPA, Cesare, 2007, vol. 2, p. 226.

70 "En la Medalla de Tito puede verse una mujer con un timón y un globo". RIPA, Cesare, 2007, vol. 2, p. 226.

71 MENDO, Andrés, 1662, p. 63 (documento 71).

72 SANTO TOMÁS, Summa Theologica [40997] IIa-Ilae q. 47 a. 10 co (1960, p. 57).

73 MATEO PALACIOS, Ana, 2013, p. 70.

${ }^{74}$ E savi home s'aperte / qu'en dar conseyl pese gran re, / e ben l'esgarde e be serque, / per tal que nuilla res no y berque, PRADAS, Daude de, 1879, p. 28 (vv. 276-279).

75 PRADAS, Daude de, 1879, pp. 80-81 (vv. 1344-1349).

76 RIPA, Cesare, 2007, vol. 1, p. 218. 
Dicha descripción nos recuerda al famoso cuadro de Tiziano de la Alegoría de la Prudencia (1565, Londres, National Gallery), ${ }^{77}$ así como al jeroglífico de Valeriano, el cual Ripa también tiene en cuenta para su imagen del Consejo: "Dichas tres cabezas, de Can, de León y de Lobo, se toman de Pierio, como símbolo de la Prudencia, que con los tres tiempos que dijimos se relaciona" ${ }^{78}$ Estas tres cabezas mantienen el mismo significado que el aspecto trifaz de la Prudencia. ${ }^{79}$ Como novedad, Ripa presenta una relación que hasta ahora no hemos visto, la imagen tricéfala de Minerva:

Es común opinión que los Antiguos, mediante la imagen de Minerva puesta junto a un olivo, pretendían representar la Sabiduría según la conocían (...) la imaginaron provista de tres cabezas, sirviendo éstas respectivamente para aconsejar a los otros, para entender por uno mismo la verdad de las cosas y en fin para actuar de acuerdo con la virtud..$^{80}$

El hecho de concebir a Minerva tricéfala aúna los dos antecedentes visuales clásicos que tiene la Prudencia: Atenea/Minerva y Jano. No es sorprendente que se adjudique a Minerva -como representante de la Sabiduría- la trifaciliadad de la Prudencia, si se tiene en cuenta que ambos términos eran tratados como sinónimos por muchos pensadores de la Antigüedad e incluso del medievo. En la Edad Media, son múltiples las representaciones de la Sabiduría ${ }^{81}$ como sustituta de la Prudencia en los casos en los que completa el elenco de las Virtudes Cardinales.

Otra de las partes de la Prudencia es el Conocimiento, por lo que Bono Giamboni, en I/ libro de' vizi e delle virtudi (s. XIII), lo define del siguiente modo:

Per Buono conoscimento si conosce la buona cosa dalla ria, o la migliore dalla buona, o la pig[g]liore dalla meno rea in questo modo. Tu hai a fare una cosa per al quale si possono molte vie tenere, e dubiti qual è la migliore. Ricorri a questa virtù ch'è detta Buono conoscimento, ed immagina bene il fato c'hai tra le mani, e pigliane verace intendimento; e per sottigliezza di tuo ingegno ne conoscerai la migliore via. ${ }^{82}$

El Conocimiento suele visualizarse en la Prudencia como un objeto lumínico, generalmente una antorcha o una lámpara. ${ }^{83}$ La idea de la luz como fuente del conocimiento o como manifestación de la verdad, remite en sus primeras formulaciones a Platón, Plotino y en general a la filosofía neoplatónica. ${ }^{84}$ Por este motivo, el Conocimiento comparte con la imagen de la Prudencia la antorcha y el libro, tal y como Ripa lo explica: "Mujer sentada que sostiene con la izquierda una antorcha encendida, viéndose junto a ella un libro abierto, mientras lo señala con el dedo índice de su derecha". ${ }^{85}$ Sobre el libro Ripa explica que es la fuente del conocimiento ya que a través de él lo adquirimos, $^{86}$ mientras que de la antorcha expone:

La antorcha encendida significa que igual que a nuestros ojos corporales es la luz imprescindible para ver, también nuestro ojo interno, que es el intelecto, para alcanzar el conocimiento de las especies inteligibles precisa apoyarse en el instrumento extrínseco de los sentidos, especialmente en el de la vista, que en el que se simboliza mediante la luz de la antorcha. ${ }^{87}$

77 Existen numerosos estudios y propuestas de interpretación de esta obra desde que Panofsky la trató en El significado de las artes visuales, por lo que solo citaremos las referencias más recientes: Vid. ZAFRA MOLINA, Rafael, 2010, pp. 123-146; PIERGUIDI, Stefano, 2006, pp. 186-196; PUTTFARKEN, Thomas, 2005, pp. 148-149; CAMPBELL, Erin, J., 2003, pp. 261-270; RAMAN, Shankar, 2003, pp. 1-38; SASTRE VÁZQUEZ, Carlos, 2001, pp. 31-56; COHEN, Simona, 2000, pp. 46-69.

78 RIPA, Cesare, 2007, vol. 1, p. 224.

79 "Las tres cabezas (...) son símbolo de las tres principales formas de los tiempos, el pasado, el presente y el futuro (...) Pues la cabeza de León, que en medio de las otras aparece, muestra el tiempo presente, que entre el pasado y el porvenir está situado. La cabeza de Lobo simboliza el tiempo pasado, por ser éste animal de cortísima memoria, cualidad que a las cosas pasadas se refiere. Por fin, la cabeza de Can significa el tiempo por venir, pues el perro, llevado por la esperanza es cualidad que mira siempre hacia las cosas futuras". RIPA, Cesare, 2007, vol. 1, p. 223.

${ }^{80}$ RIPA, Cesare, 2007, vol. 2, pp. 281-282.

81 La consideración de la Sabiduría y la Prudencia como sinónimas también da lugar a relaciones visuales entre las visualizaciones de ambas. Sin embargo, no se trata la Sabiduría en el presente estudio puesto que no constituye una de las partes de esta virtud.

82 GIAMBONI, Bono, 1968, p. 5

83 Además, Gaucher adjudica una lámpara a la Prudence chrétienne, sobre la que explica su presencia como alusión a la parábola de las Vírgenes sabias y necias. GAUCHER, Charles-Etienne; GRAVELOT, Hubert F.; COCHIN, Charles N., 1791 , vol. 4, p. 45.

84 LEÓN COLOMA, Miguel Ángel, 1989, p. 66.

85 RIPA, Cesare, 2007, vol. 1, p. 217.

86 RIPA, Cesare, 2007, vol. 1, p. 218

87 RIPA, Cesare, 2007, vol. 1, pp. 217-218. 
Así encontramos esta parte de la Prudencia en La Connaissance (1695) de Jean Jouvenet (1695, Rennes, Palais du Parlement de Bretagne, Conseil de la Grand Chambre), portando una antorcha y un libro, y en la Iconologie (1759) de Boudard [Fig. 3], donde se explica que Le flambeau allumé qu'on lui donne, est allusit à la lumiere qu'elle répand dans les âmes, \& aux sens, par lesquels, comme le dit Aristote, les conoissances se communiquent à l'esprit. ${ }^{88}$ No obstante, no es el único modo en que se concibió la imagen del Conocimiento, ya que Ripa también lo describió sosteniendo una vara o cetro y un libro, ${ }^{89}$ atributos que también son propios de la Prudencia.

En cuanto a la Razón, Santo Tomás estableció una clara relación con la Prudencia: "Por lo tanto, para la prudencia es necesario que el hombre razone bien"..$^{90}$ Una miniatura de La ciudad de las damas de Cristina de Pizán (ca. 1405, París, BNF, ms. français 606 , fol. 2 r) nos muestra a la autora junto a la Razón, la Justicia y la Honestidad. Reconocemos a la Razón por llevar un espejo, atributo tradicional de la Prudencia. La Razón también porta un espejo en el segundo panel de Los honores (Cartonistas del círculo de Bernard van Orley, Jan Gossaert y Pieter van Aelst, ca. 1520, Segovia, Palacio de la Granja de San Ildefonso) y en la Alegoría de la Razón de Ivan Rendic (finales del s. XIX-principios s. XX). Sin embargo, Ripa no recoge el espejo como atributo de la Razón, aunque sí propone cinco visualizaciones de esta que comparten atributos con la Prudencia. En primer lugar, la Prudencia comparte con la imagen de la Razón de Estado el yelmo, según Ripa con el cual: "se indica la fortaleza y Sabiduría de la razón, pues en ella reside aquella Prudencia intelectual de nuestro ánimo que averigua y discurre los fines de las cosas, siguiendo las

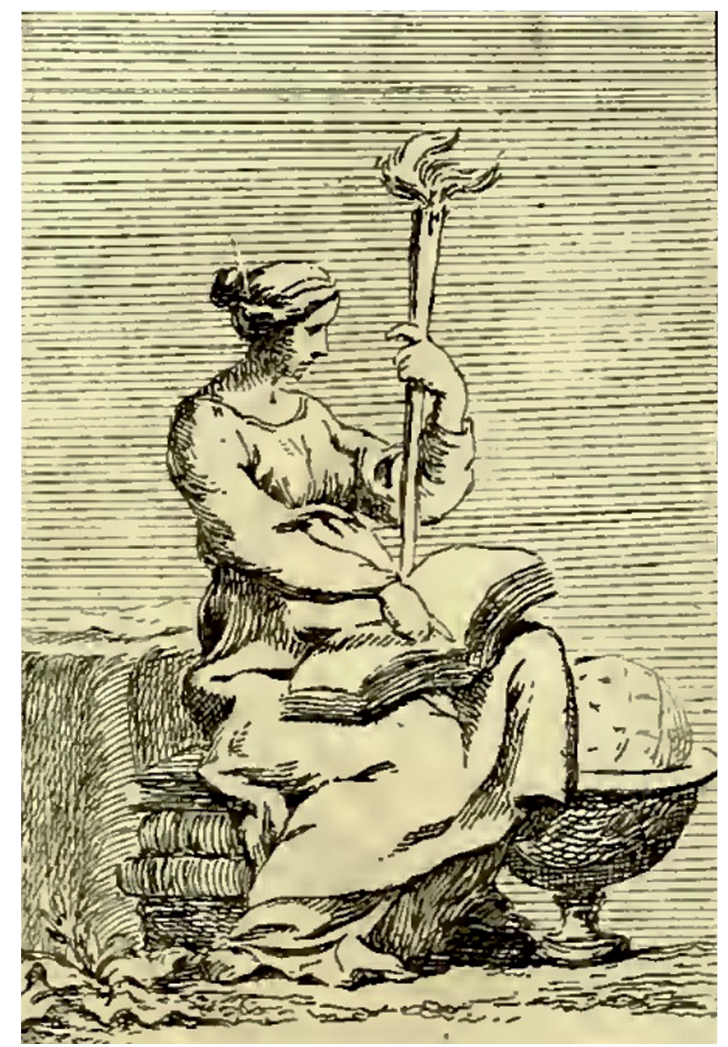

Fig. 3. Conocimiento, Iconologie, J. B. Boudard, 1759, Parma

que juzga como buenas y rehuyendo en cambio sus contrarias". ${ }^{91}$ Además del yelmo, Ripa concibe la Razón de Estado con coraza, llevando asimismo un libro y un león, ${ }^{92}$ como en ocasiones la Prudencia, aunque en este caso con significados distintos. ${ }^{93}$ Imagen semejante le atribuye Bourdard al Razona-

\footnotetext{
88 BOUDARD, Jean Baptiste, 1759, vol. 1, p. 111.

89 "Mujer que sostiene con la diestra una vara o un cetro, y con la siniestra un libro. Esto significa que el conocimiento de las cosas se adquiere mediante la atenta lectura, lográndose así el dominio de las facultades del ánimo". RIPA, Cesare, 2007, vol. 1, p. 218.

90 SANTO TOMÁS, Summa Theologica [41098] IIa-Ilae q. 49 a. 5 co (1960, p. 61).

91 RIPA, Cesare, 2007, vol. 2, p. 248.

92 "Mujer armada de Coraza, Yelmo y Cimitarra. Debajo de la armadura ha de llevar un faldellín de color azul turquesa enteramente bordado y adornado con orejas y ojos. Con la diestra sostendrá una varilla, con la cual habrá dado algún revés o mandoble sobre unos capullos de adormidera, viéndose cómo los mayores y más altos han quedado tronchados por la vara y caídos en tierra, permaneciendo intactos por el contrario los que eran más pequeños. Tendrá además la diestra firmemente apoyada en la testa de un León, y a sus pies habrá un libro puesto al lado contrario, llevando por último inscrita la palabra lus que se peude leer sobre su lomo". RIPA, Cesare, 2007, vol. 2, p. 249.

93 "Se ha de poner un León a un lado de esta figura, pues su natura es semejante a la de aquellos que, en atención a la razón de Estado, intentan de continuo ser superiores a todos, simbolizándose también con el mentado animal la vigilante custodia y fortaleza que se debe mantener para lograr la conservación y dominio del Estado [...]. El antedicho Libro, con la palabra lus sobre su lomo, claramente nos muestra que en ciertas ocasiones es posible posponer las normas que gobiernan y determinan la razón civil, para obtener el reinado, o también por alcanzar alguna pública utilidad". RIPA, Cesare, 2007, vol. 2, p. 250.
} 
miento, también dotado con un libro con el mismo significado que cuando acompaña a la Prudencia. ${ }^{94}$ Respecto al yelmo, la coraza y el hecho de que la Razón se represente armada, nos recuerda a la imagen de Atenea/Minerva, la cual no solo ha sido referente para la configuración de la imagen de la Prudencia sino también para la de sus partes. Muestra de ello es que otra de las propuestas de Ripa para la imagen de la Razón también lleva armadura, reconociendo este autor la inminente influencia de la diosa clásica: "Se pinta joven y provista de armadura por hallarse defendida y mantenida con la fuerza y vigor de la Sabiduría, tomándose muchas veces entre los Antiguos la armadura exterior con el presente significado, como ocurría en el caso de la figura de Palas y otros semejantes". ${ }^{95}$ Asimismo, la Razón también lleva una espada como "equivalente del vigor de la razón"96 0 , como variante, una lanza y un escudo. ${ }^{97}$ Semejante imagen encontramos en la Iconologie de Boudard, donde la Razón también viste coraza y sostiene una espada mientras agarra unas serpientes, imagen de los Vicios a los que se enfrenta. ${ }^{98}$ Es curioso que en tres de las propuestas de Ripa la Razón lleva un freno, atributo tradicionalmente identificado con la Templanza, aunque cabe recordar la vertiente temperada de la Prudencia e incluso la presencia del freno en alguna imagen alusiva a esta virtud. En el símbolo CCXLVI de Bocchi encontramos unos caballos domados por un freno, de ma- nera muy semejante a la que Ripa justifica la presencia de este atributo en la imagen de la Razón:

Se pintará una Matrona de bellísimo aspecto que con la diestra ha de sostener un azote y con la izquierda un freno; pues así como el caballo se doma con el freno, haciéndose lo mismo con los niños con el azote, así también la Razón doma y gobierna las pasiones perversas de nuestro ánimo. ${ }^{99}$

Así la vemos en El poder de la paz de Joannes GaIle (1648, Ámsterdam, Rijkmuseum), sosteniendo un freno e indicando con una vara a la Prudencia lo que ha de hacer. Por otro lado, la presencia de la serpiente en la imagen de la Razón tiene un significado distinto a cuando acompaña a la Prudencia, ya que en este caso hace referencia al mal que debe ser controlado mediante el freno. ${ }^{100}$ Con un sentido diferente, Borja también representa una serpiente en alusión a la Razón en Lethale venenum [Mortal veneno], pero dotando a esta de dos cabezas, queriendo significar que tan solo una debe gobernar. ${ }^{101}$ Cabe recordar que la serpiente también estaba presente en la imagen de Atenea/Minerva, constituyendo esta diosa el principal referente visual de la Prudencia y de la mayoría de sus partes. En el caso de la Sagacidad, ${ }^{102}$ además de adoptar la lanza de Atenea/Minerva, la personificación de esta parte sostiene una imagen de la diosa como signo del ingenio tal y como Ripa explica: "Por ello, para mostrar esta imagen

\footnotetext{
${ }^{94}$ Boudard concibe el Razonamiento como Ce sujet se personnifie par un homme d'âge virile, vêtu d'une robe longue, \& tenant sur ses genoux un libre ouvert, dont il montre un endroit. II est en action de parler avec chaleur, \& est assis sur un cube de Pierre sur lequel est gravée cette inscription: IN PERFECTO QUIESCIT. En cuanto al libro, es explicado como Ce sont les preuves que la raison employe pour justisier, éclaircir, ou confirmer ce qu'elle a établi. BOUDARD, Jean Baptiste, 1759, vol. 3, p. 90.

${ }_{95}$ RIPA, Cesare, 2007, vol. 2, p. 247.

96 RIPA, Cesare, 2007, vol. 2, p. 247.

97 "Una joven vestida con clámide de oro así como ropajes de colores celestes. Estará sosteniendo con la diestra una lanza y abrazando un laurel con la siniestra, del cual cualça un escudo en cuyo centro se pinta el rostro de Medusa. Ha de tocar su cabeza con un yelmo, poniéndosele una llama por cimera". RIPA, Cesare, 2007, vol. 2, p. 247.

98 On peint la raison sous la figure d'une Mâtrone vêtue d'une côte d'armes, \& ayant sur sa poitrine l'égide de Minerve, pour marquer qu'elle est une force superieure de l'ame, réglée \& défendue par la sagesse. Elle tient une épée flamboyante dont elle menace les vices, contre lesquels elle est sans cesse en guerre, \& qui sont figurés par plusieurs serpents aîlés qu'elle foule sous ses pieds, \& qu'elle tient enchaînés. BOUDARD, Jean Baptiste, 1759, vol. 3, p. 89.

99 RIPA, Cesare, 2007, vol. 2, p. 248.

100 RIPA, Cesare, 2007, vol. 2, p. 246. Aunque la serpiente como atributo de la Prudencia representa la Cautela que la caracteriza, también ha sido considerada como emblema del Mal que reconoce esta virtud para evitarlo escogiendo así el Bien. Vid. COMENIUS, Johann A., 1887, p. 138 y HOLMES, William, 1868, p. 111.

101 BORJA, Juan de, 1680, pp. 312-313.

102 "Mas igual que la docilidad va encaminada a disponer al hombre para recibir de otro una apreciación recta, la sagacidad se propone la adquisición de una recta opinión por propia iniciativa, pero entendida la sagacidad en el plano de la vigilancia o eustochia, de la que es parte. En efecto, la vigilancia o eustochia deduce bien en toda clase de asuntos; la sagacidad, en cambio, es habilidad para la rápida y fácil invención del medio, como vemos en el Filósofo en I Poster. Sin embargo, hay un filósofo que considera la sagacidad como parte de la prudencia, y la toma en el sentido de vigilancia en toda su amplitud. Por eso dice que la sagacidad es un hábito por el que de pronto se sabe hallar lo que conviene".
}

SANTO TOMÁS, Summa Theologica [41090], IIa-Ilae q. 49 a. 4 co (1960, p. 61). 
se representará a Minerva, en la actitud acostumbrada, mas teniendo bajo su lanza una esfinge, tal como hemos dicho". ${ }^{103}$ Por otro lado, Ripa presenta otra variante de la Sagacidad ${ }^{104}$ que sostiene una rama de morera y se acompaña de un león, atributos que también comparte con la Prudencia. ${ }^{105}$

Santo Tomás concibió la Razón como parte de la Prudencia al igual que el Entendimiento, poniendo ambas partes en relación: "En efecto, el entendimiento recibe el nombre de la penetración íntima de la verdad, mientras que la razón implica inquisición y discurso. Por eso uno y otro van incluidos como partes de la prudencia, conforme se deduce de lo expuesto". ${ }^{106}$ Aunque hasta Gracián en su aforismo 25 -“Ser buen entendedor (...). El prudente debe saber entenderlas: refrena la credulidad en las cosas favorables y la estimula en las odiosas"-, ${ }^{107}$ expone la necesidad del Entendimiento en la Prudencia, este ha sido denominado mayoritariamente como Intelecto, como ya vemos en santo Tomás. Cabe recordar que los pensadores no coinciden en el número y denominación de las partes de la Prudencia ya que, aunque suelen hacer referencia prácticamente a las mismas, emplean términos distintos para designarlas. En el segundo panel de Los honores, dedicado a la Prudencia, el Intelecto lleva un caduceo y un libro, atributos propios de la virtud a la que pertenece. Sin embargo, Ripa no recoge esta visualización del Intelecto, aunque sí propone otras dos que también presentan paralelismos con la Prudencia. Por un lado, al igual que la Razón, el Intelecto se representa con coraza ${ }^{108}$ y yelmo, ${ }^{109}$ claro signo de los precedentes visuales clásicos. Pero, por otro lado, otra variante de la imagen del Intelecto se acompaña de un águila, claro signo de su sinonimia con el Entendimiento como Ripa explica: "El mostrar el Águila con el dedo simboliza el acto de entender; pues es lo propio del Intelecto". ${ }^{110}$ Este animal, aunque no muy frecuentemente, también acompaña a la Prudencia en alguna ocasión. ${ }^{111}$ En esta misma variante que propone Ripa, ${ }^{112}$ el Intelecto también lleva una llama sobre su cabeza, corona y cetro. La presencia la llama como signo de la luz ya la veíamos en la antorcha, lámpara o cirio que portan la Sabiduría y la Prudencia, y respecto a la cual Ripa explica:

Representa la llama el natural deseo de saber que nace de la capacidad y la virtud intelectiva, la cual aspira siempre a las otras más elevadas, y divinas; a condición de no dejarse desviar por los sentidos, que gustosos al punto le obedecen, entreteniéndose en la contemplación de las cosas terrenas. ${ }^{113}$

Pero, en cuanto al cetro y la corona, no hacen referencia a la Prudencia gubernativa aunque sí son signo de gobierno, pero de uno mismo: "La corona y el cetro son signos del dominio que ostenta y que mantiene sobre todas las pasiones del ánimo, así como sobre la propia voluntad; pues esta nada desea ni apetece sin que previamente le venga propuesto y sugerido por el Intelecto". 114 Por su

103 RIPA, Cesare, 2007, vol. 2, p. 75.

104 RIPA, Cesare, 2007, vol. 2, p. 75. Accortezza.

105 En cuanto al significado de la morera en la imagen de la Prudencia vid. MONTESINOS, María, 2015, pp. 113-120.

106 SANTO TOMÁS, Summa Theologica [41101], Ila--llae q. 49 a. 5 ad. 3 (1960, p. 60).

107 GRACIÁN, Baltasar, 1994, p. 15.

108 "Hombre armado de coraza y revestido de oro. Llevará sbre a cabeza un yelmo dorado, sosteniendo u asta con la mano. El hombre que decimos, tal como queda descrito, muestra la perfección del intelecto; el cual, armado de sabios consejos y decisiones, fácilmente se defiende de cuanto intente dañarle, resplandeciendo además en todas las acciones que realiza, si son loables o bellas. También se pone armado porque tanto en la guerra con en la paz es igualmente imprescindible". RIPA, Cesare, 2007, vol. 1, pp. 531-532.

109 "Lleva el yelmo dorado en la cabeza mostrando así que el Intelecto hace al hombre más sabio y elevado, dotándolo de mayor solidez y volviéndolo más agradable ya preciado a los ojos de cuantos le conocen; pues éstos, conociendo su valor, como al oro lo valoran, viéndolo tan sólido y recto como el acero". RIPA, Cesare, 2007, vol. 1, p. 532.

110 RIPA, Cesare, 2007, vol. 1, p. 533.

111 Muestra de ello es la Prudencia que encontramos en la Wallfahrtskirche Frauenberg (s. XVIII) y la de Jacques Sarazin (16481658, Chantilly, MCo).

112 "Gallardo jovencito vestido con ropas de oro, que lleva una corona del mismo metal, o sino una corona trenzada de hojas de mostaza. Rubios serán sus cabellos, dispuestos y adornados con muy bellos bucles, saliéndole de la parte más alta de la cabeza una llama de fuego. Con la diestra sostendrá un cetro, y con la siniestra señala un Águila que junto a él se pone". RIPA, Cesare, 2007, vol. 1, pp. 532-533.

113 RIPA, Cesare, 2007, vol. 1, p. 533

114 RIPA, Cesare, 2007, vol. 1, p. 533 
parte, Bourdard combinó las dos visualizaciones de Ripa en su alegoría del Intelecto [Fig. 4], dotándola de un yelmo con una llama, ${ }^{115}$ un cetro ${ }^{116}$ y un águila. ${ }^{117}$

Por otra parte, aunque a primera vista puede parecer que el Intelecto y la Inteligencia son conceptos muy cercanos, visualmente se representan de modo muy diferente. Santo Tomás definió la Inteligencia no "como facultad intelectiva, sino en cuanto a que implica cierta estimación recta de algún principio último conocido por sí mismo; así hablamos de la inteligencia de los primeros principios". ${ }^{118}$ Aunque en el segundo panel de Los honores la Inteligencia lleve un fuelle entre sus manos, Ripa la concibió sosteniendo una esfera y una serpiente, ${ }^{119}$ la cual "enseña que para alcanzar la comprensión de las cosas más altas y sublimes, es preciso primero arrastrase por tierra, como lo hacen las serpientes". ${ }^{120}$ Con ello, Ripa quiere significar que la serpiente representa el esfuerzo necesario para alcanzar el saber, reflexión que Cristina de Pizán ya había considerado siglos antes: "La serpiente alude al esfuerzo y al gran trabajo que pesan sobre el estudioso, y a los cuales ha de dominar también, para adquirir el saber". ${ }^{121}$ Por eso, Nicolò Bambini representó la Inteligencia (1682, Venecia, Palazzo Ca' Pesaro, Camera sul Canal Grande) conforme Ripa la había concebido con serpiente y esfera. Igualmente, Boudard visualizó la Inteligencia sosteniendo una esfera armilar mientras a sus pies descansan una serpiente y unos escritos [Fig. 5], signos de la Experiencia, el Conoci- miento y la Prudencia que la caracterizan. ${ }^{122} \mathrm{Sin}$ embargo, aunque Gaucher también concibió la Inteligencia sosteniendo una esfera armilar, también ideó una visualización más cercana a la que Ripa y Boudard proponen para el Intelecto, ya que está coronada por una llama y acompañada por un águila. ${ }^{123}$ Asimismo, encontramos representada la Inteligencia portando un libro y una esfera armilar en el Istituto di Santa Maria Riparatrice de Florencia, atributos propios de la Prudencia derivados de la asociación de las Virtudes con las Artes Liberales. En cuanto a la serpiente, aparece relacionada con la Sabiduría en el Fisiólogo, ya que formaba parte de la imagen de Atenea/Minerva, lo que Sebastián no duda en destacar en su edición de esta obra:

Cristo reconoce y proclama la relación que este animal ha tenido con la ciencia y la sabiduría, lo que también manifestaron las civilizaciones antiguas, y con este sentido pasó a la ideología cristiana, pero, empleada para el mal como era propio de Satán en su afán de engañar a los hombres. ${ }^{124}$

Es curioso señalar que, a pesar de que la serpiente provenga de Atenea/Minerva, la cual representa la Sabiduría y la Prudencia, a esta primera Ripa no le adjudica la serpiente como atributo. De este modo, visualmente no se concibe la Inteligencia como un don innato sino como fruto de la experiencia, la cual requiere el esfuerzo que representa la serpiente en este caso o el estudio de la música en la otra variante de Ripa:125 "Se muestra así que la Inteligencia nace generalmente de la expe-

\footnotetext{
115 Il se représente allégoriquement par un beau jeune homme coéffé d'un casque d'or, allusif à la pureté de son être. La flamme qui fort de ce casque, signifie l'ardent desir de s'élever. BOUDARD, Jean Baptiste, 1759, vol. 2, p. 133.

116 Le sceptre qu'on lui donne indique l'autorité qu'il a sur lui-même \& sur ses passions. Ibid.

117 de vaincre pour ainsi dire le vol de l'aigle, que pour cette raison on fait retenir par cette figure. Ibid.

118 SANTO TOMÁs, Summa Theologica [41074], IIa-Ilae q. 49 a. 2 co (1960, p. 57).

119 RIPA, Cesare, 2007, vol. 1, p. 533.

120 RIPA, Cesare, 2007, vol. 1, p. 533.

121 PIZÁN, Cristina de, 2005, p. 112.

122 Cette figure se peint les yeux tournes vers le ciel, qu'elle contemple; elle tient une sphere, \& la robe est d'étoffe d'or; les écrits qui sont à ses pieds, entre lesquels rampe un serpent, marquent qu'elle est le fruit de l'expérience \& de l'étude; \& qu'on doit à l'exemple du serpent, qui est un des emblêmes de la prudence, aller terre à terre dans les príncipes qui conduisent à la connoissance des hautes sciences. BOUDARD, Jean Baptiste, 1759, vol. 2, p. 134.

${ }^{123}$ Fille de l'observation et mère de nos connoissances, c'est elle qui doit diriger toutes nos opérations; ce que désigne le sceptre, symbole du commandement, qu'on lui fait tenir. La sphère que porte I'Intelligence, ainsi que les attributs des sciences placés auprès d'elle, annoncent que c'est à cette faculté de l'ame qu'on doit leur utilité: la flamme qui brille sur la tête de cette figure symbolique, peut être considerée comme une étincelle de l'Intelligence céleste. Entrainée par l'amour de la verité, I'Intelligence se porte quelquefois auxx spéculations les plus sublimes; c'est ce qu'on a tâché d'exprimer par l'aigle qui fixe l'astre du jour, jusques auquel il paroît vouloir quelquefois s'élever. GAUCHER, Charles-Etienne; GRAVELOT, Hubert F.; COCHIN, Charles N., 1791, vol. 3, p. 17.

124 SEBASTIÁN, Santiago, 1986, p. 83.

125 "Mujer que con la diestra ha de sostener un laúd, y con la siniestra una tablilla repleta de inscripciones". RIPA, Cesare, 2007, vol. 1, p. 534.
} 


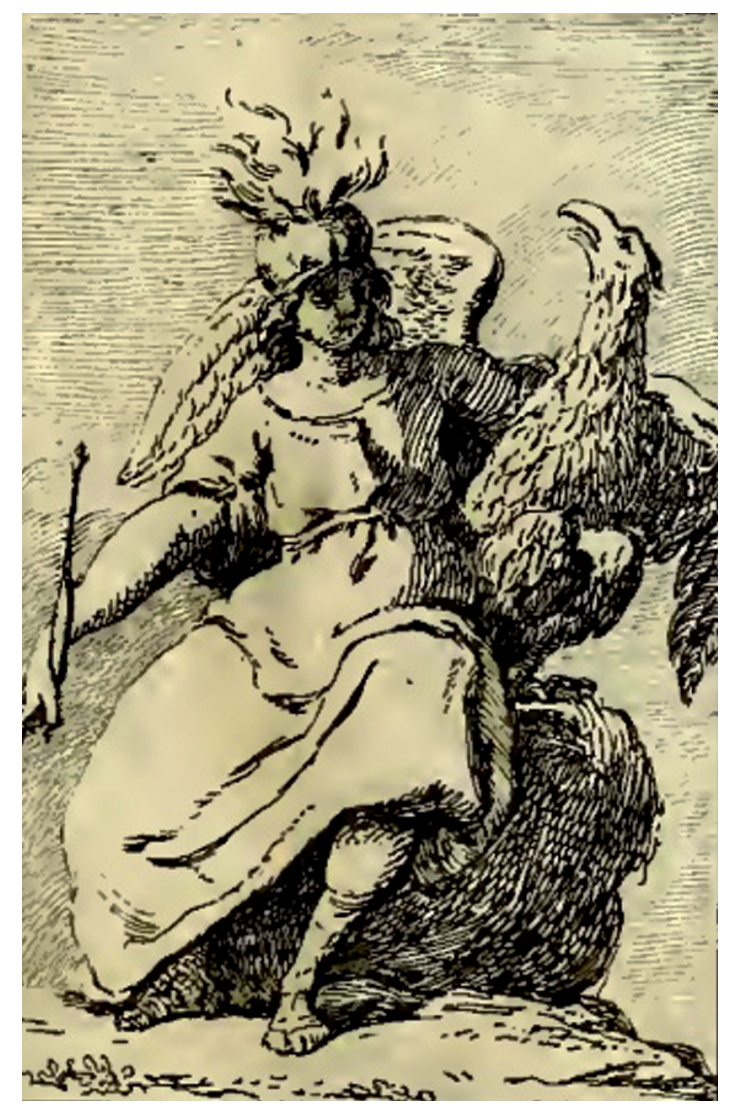

Fig. 4. Intelecto, Iconologie, J. B. Boudard, 1759, Parma.

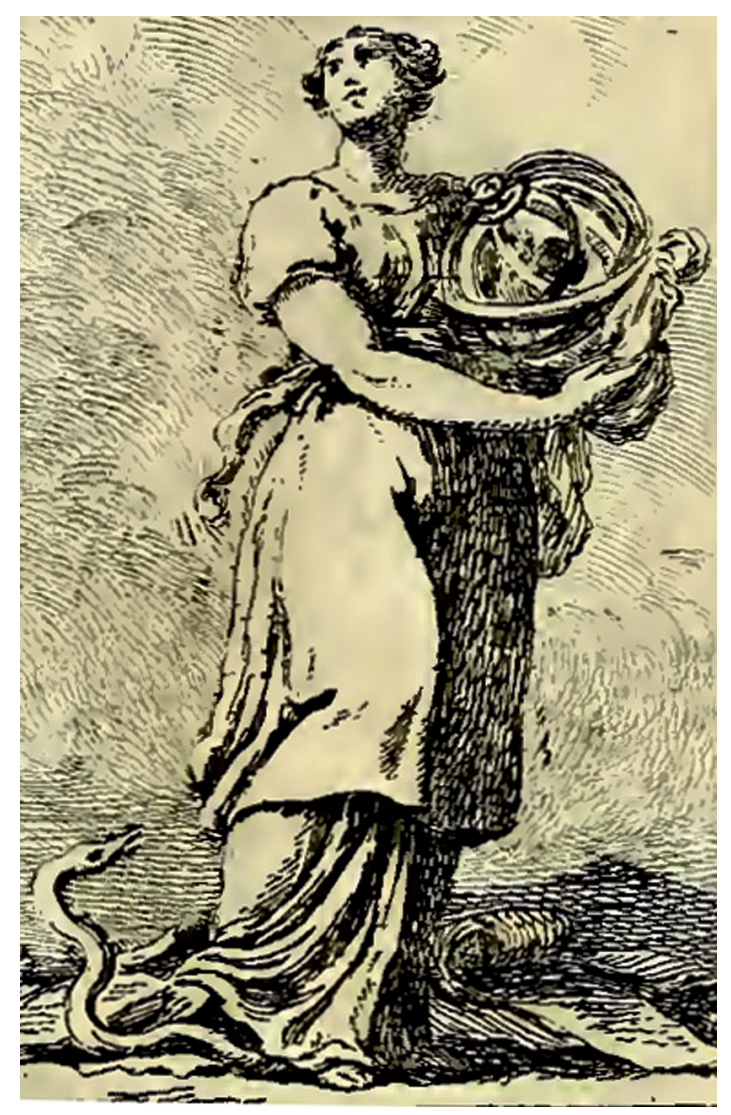

Fig. 5. Inteligencia, Iconologie, J. B. Boudard, 1759, Parma. riencia, o en su caso del estudio, como fácilmente se comprende a partir de las cosas que en su mano se ponen". ${ }^{126}$ Por otro lado, cabe recordar que la Experiencia no siempre es considerada parte de la Prudencia por los pensadores como santo Tomás, pero tanto Aristóteles, ${ }^{127}$ quien sí la consideró parte, como Santo Tomás explican que es una característica indispensable de esta virtud. Encontramos la Experiencia visualizada de diferente modo, pero siempre con atributos propios de la Prudencia. Ripa la representa con una llama, lo que nos recuerda a la antorcha del Conocimiento, el Intelecto, la Sabiduría o la propia Prudencia. Pero en el Palazzo Ca' Pesaro de Venecia (1682, Camera sul Canal Grande) Nicolò Bambini representó la Experiencia portando un libro, emblema del saber y el conocimiento, así como tradicional atributo de la virtud que nos ocupa. Sin embargo, la Experiencia también se visualiza a través de la imagen de la Deliberación, otra de las partes de la Prudencia. Bono Giamboni, en Il libro de' vizi e delle virtudi (s. XIII), definió la Deliberación como: Per Buono esaminamento si conosce il meglio delle cose, quan s'isaminano $i$ contrari, cioè tutte le cose che possono fara rea la cosa s'hai a fare. ${ }^{128}$ Aunque Ripa no recoge la Deliberación en sí, esta se manifiesta a través del apartado "Distinción del bien y del mal". ${ }^{29}$ Ripa describe dicho concepto como una mujer de edad madura que lleva un cedazo y un rastrillo. El hecho de que se personifique como una mujer madura muestra la necesidad de la Experiencia en el ejercicio de la Prudencia, cuya parte es la Deliberación, encargada de la distinción del Bien y del Mal:

\footnotetext{
126 RIPA, Cesare, 2007, vol. 1, p. 534.

127 ARISTÓTELES, Ética nicomáquea, VI, 9, 1142a 15 (1985, p. 278).

128 GIAMBONI, Bono, 1968, p. 6.

129 RIPA, Cesare, 2007, vol. 1, p. 289.
} 
Se representa en su edad madura y vestida con hábito grave, por hallarse dotada dicha edad de mayor capacidad y más rectas razones útiles para distinguir entre el bien y el mal, entre lo bueno y lo malo. Pues en la juventud nos vemos arrastrados por los excesos de las fervientes concupiscencias y pasiones, y en cambio en la vejez por los delirios sin fin del intelecto. ${ }^{130}$

Sin embargo, el atributo principal que representa dicha distinción necesaria para la deliberación es el cedazo o la criba, como explica Ripa remontándose a sus precedentes de la Antigüedad:131 "Bien se corresponde el cedazo con esta figura, significándose con ello la distinción entre el bien y el mal. ${ }^{132}$ Cabe recordar que la criba es un atributo característico de la Prudencia en cuanto a su imagen en el ámbito de la "nueva visualidad", ${ }^{133}$ representando así la Deliberación. Esta parte es la necesaria antes de Ilevar a cabo la Elección, ${ }^{134}$ otra de las partes y principal función de la Prudencia. Sin embargo, la personificación de la Elección tan solo comparte con la Prudencia la presencia de la serpiente, ${ }^{135}$ como vemos en la Iconologie de Bourdard, aunque en este caso la serpiente marca uno de los caminos entre los que debe elegir: Son vêtement viole test le symbole de la prudence qui lui convient [...]. On la peint assise entre deux chemins, dans l'un desquels rampe un serpent, \& dans l'autre est un arbrisseau verdoyant qu'elle indique d'une main, en montrant de l'autre. ${ }^{136}$ Además, la
Elección sostiene una filacteria en la que se puede leer Virtutem eligo, haciendo referencia a la decisión prudente y correcta que se ha de tomar siempre.

También la "nueva visualidad" concibió la Prudencia con una bolsa de monedas a sus pies y sosteniendo un compás, atributos que sostiene la Circunspección, otra de las partes de la Prudenciali37 en el segundo panel de Los honores. La Circunspección es normalmente conectada con la abolición de la avaricia (aunque manteniendo la liberalidad) y es cercana a la Precaución, la cual previene de errar frente al Vicio. ${ }^{138}$ Así la concibe Santo Tomás, quien explica sobre esta última parte: "Por eso la prudencia necesita de precaución para aceptar el bien y evitar el mal". ${ }^{139}$ La Precaución y la Cautela se han empleado como términos sinónimos para designar esta parte de la Prudencia. Pues es la Cautela quien, sosteniendo un espejo, se incluye en el séquito de damas que acompañan a la Prudencia en el segundo panel de Los honores. Por último, la Docilidad es parte de la Prudencia en cuanto a que tiene el don del Buen Consejo y para dejarse aconsejar es necesario ser un tanto dócil, como santo Tomás lo explica: "Por la prudencia, según hemos dicho, impera el hombre no solamente sobre los demás, sino también sobre sí mismo. Por eso se da también, como hemos probado, en los súbditos a cuya prudencia corresponde la docilidad". ${ }^{140}$ La Docilidad también presenta

\footnotetext{
130 RIPA, Cesare, 2007, vol. 1, p. 289.

131 "Ya se sirve de este símbolo Claudio Paradino cuando se pregunta: Ecquis discernit utrumque? [¿Acaso alguien distingue una cosa de otra?] ¿Qué es lo que mejor distingue, divide o separa una cosa de otra, el bien del mal? Aquello que actúa como cedazo, separando el buen grano de la perniciosa cizaña, cosa que no hacen las personas inicuas y malvadas, quienes sin emplear la criba de la razón, todo junto y revuelto lo consideran. Por ello tomó Pierio el cedazo como jeroglífico del hombre de perfecta sabiduría, porque un idiosa no es capaz de discernir el bien del mal, ni sabe investigar los secretos de la Naturaleza. De ahí viene aquel proverbio que procede de Galeno: Stulti ad cribrum [Los necios a la criba] [...] Los sacerdotes Egipcios, para obtener sus vaticinios con sagaces conjeturas, solían tomar en la mano un cedazo, sobre el cual estaba inscrito aquel Adagio Griego que dice: Bribro divinare [Adivinar por la criba]". RIPA, Cesare, 2007, vol. 1, p. 289.

132 RIPA, Cesare, 2007, vol. 1, p. 289.

133 Entendemos por "nueva visualidad" la corriente visual francesa surgida en el siglo XV que visualizó a las Virtudes apartándose de la tradición (a excepción de la Justicia).

134 Buona elezione è vertú che nasce di Prudenza, sanza la quale il conoscimento del bene e del male e 'l conoscimento della migliore cosa varebbe poco se la lezione non seguitasse del bene e della cosa migliore; ma seguitandosi sipo 'I conoscimento l'elezione della buona overo migliore cosa c'ha conosciuto, compie Prudenzia la bontà e la virtú sua. GIAMBONI, Bono, 1968, p. 6.

135 Mujer anciana, cadena con un colgante de corazón en el que está escrita la inscripción 'Virtutem Eligo'. A su lado tiene una serpiente y un roble". BAR, Virginie, 1999, p. 39.

136 BOUDARD, Jean Baptiste, 1759, vol. 1, p. 176.

137 "Como incumbe a la previsión descubrir lo que es de suyo adecuado al fin, incumbe a la circunspección considerar si es adecuado al fin dadas las circunstancias actuales. Lo uno y lo otro entraña dificultad, y por esa razón figuran las dos como partes distintas de la prudencia". SANTO TOMÁS, Summa Theologica [41117], IIa-Ilae q. 49 a. 7 ad 3 (1960, p. 60).

138 TUVE, Rosemund, 1963, p. 270.

139 SANTO TOMÁS, Summa Theologica [41122], IIa-Ilae q. 49 a. 8 co (1960, p. 61).

140 SANTO TOMÁS, Summa Theologica [41085], Ila-Ilae q. 49 a. 3 ad $3(1960$, p. 60).
} 
variantes en su visualización, ya que Ripa le adjudica un espejo como atributo [Fig. 6], al igual que Gaucher, quien explica al respecto:

Una joven, cuyo semblante anuncia la dulzura, y dejándose poner un yugo sobre las espaldas, es el emblema con que los iconologistas representan la Docilidad. Como esta cualidad * es necesaria para aprovechar los consejos, se coloca un espejo sobre el pecho de la figura que la representa; alusión á la propiedad del espejo de reflejar las imágenes de los cuerpos. ${ }^{141}$

No obstante, aunque por lo general la Docilidad sostiene un espejo, en el segundo panel de Los honores la vemos sosteniendo un libro y un manojo de varas. En todo caso, a pesar de las variaciones, la Docilidad, al igual que las otras partes expuestas, presentan una amplia variedad de atributos en común con la imagen de la Prudencia, entre los cuales destacan la antorcha (lámpara o cirio), el libro, la bifacialidad y aquellos derivados de la imagen de Atenea/Minerva (coraza, yelmo, lanza, serpiente...).

Por lo tanto, los atributos que porta la Prudencia son clara manifestación visual de las partes que la componen, así como la visualización de estas ofrece conexiones con la propia imagen su virtud principal. Para establecer más conexiones entre la Prudencia y sus partes sería necesario precisar los diferentes tipos iconográficos que configuran las visualizaciones de sus partes, así como la continuidad y variación de los mismos.

\section{Bibliografía y fuentes}

AMBLARD, Paule, Le Pèlerinage de Vie Humaine. Le songe très chrétien de l'abbé Guillaume de DigulleviIle, París: Flammarion, 1998.

ARISTÓTELES, De las Virtudes y los Vicios, Madrid: Imp. de L. Rubio, 1931 (Traducción de Francisco Gallach Palés).

ARÍSTOTELES, Ética nicomáquea, Madrid: Gredos, 1985 (Traducción de Emilio Lledó Íñigo).

BAR, Virginie, Dictionnaire iconologique. Les allégories et les symboles de Cesare Ripa et Jean Baudoin, Dijon: Éditions Faton, 1999.

BORJA, Juan de, Empresas morales, Bruselas: Francisco Foppens, 1680.

BOUDARD, Jean Baptiste, Iconologie, Parma: Philippe Carmignani, 1759.

CAMPBELL, Erin J., "Old age and the politics of judgment in Titian's 'Allegory of Prudence'", Word and Image, 2003, 19, pp. 261-270.

CARTARI, Vicenzo, Imagines deorum, Lugduni, Apud Stephanum Michaelem, 1581.

CARVALHO, Armando Luís, "Rey y 'Totalidad Nacional' en la obra de Don Duarte: en torno a los conceptos de

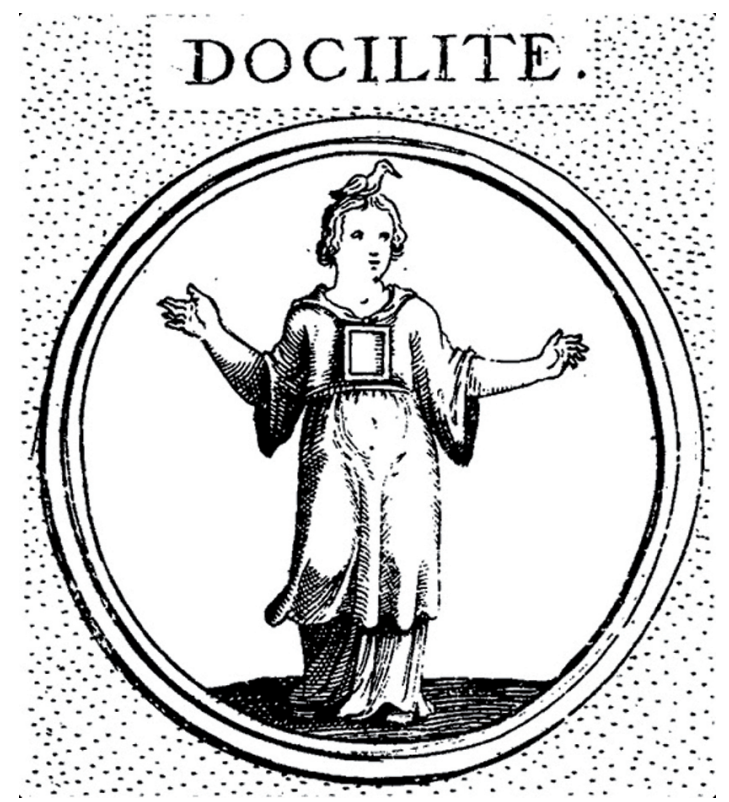

Fig. 6. Docilidad, Iconología, Cesare Ripa, 1643, París.

de prudencia y consejo", Hispania: Revista española de historia, 2007, 67, 227, p. 940

CHAUCER, Geoffrey, Canterbury Tales, Nueva York: Garden City, 1934.

CICERÓN, Los oficios, Buenos Aires: Espasa-Calpe, 1946 (Traducción de Manuel de Valbuena).

CICERÓN, La invención retórica, Madrid: Gredos, 1997 (Traducción de Salvador Núñez).

COHEN, Simona. "Titian's London 'Allegory' and the three beasts of his 'selva oscura'", Renaissance Studies, 2000, 14, pp. 46-69.

DELHAYE, Philippe, "La vertu et les vertus dans les oeuvres d'Alain de Lille", Cahiers de civilisation medievale, 1963, 6, 1, p. 15.

COMENIUS, Johann A., Orbis pictus, Nueva York: C.W. Bardeen, 1887.

DUARTE, Dom, Leal Conselheiro, Lisboa: IN/CM, 1998, pp. 209-211.

FLORIANI, Peter J., A Twenty-first Century Tree of Virtues, Milán: Ambrosian University Press, 2014.

GIAMBONI, Bono, /l libro de' vizi e delle virtudi e /l trattato di virtu e di vizi, Turín: G. Einaudi, 1968.

GRACIÁN, Baltasar, El arte de la prudencia: oráculo manual, Madrid: Temas de Hoy, 1994.

GAUCHER, Charles-Etienne; GRAVELOT, Hubert F.; COCHIN, Charles N., Iconologie par figures, París: Lattré Graveur, 1791.

GUZMÁN, Francisco de, Triumphos morales, Alcalá de Henares: Casa de Andrés, 1565.

HOLMES, William, Religious emblems and allegories, Londres: W. Tegg, 1868.

HOURIHANE, Colum, Virtue \& vice: the personifications in the Index of Christian art, Princeton N. J.: Index of

141 PASTOR, Luis G., 1866, p. 103. GAUCHER, Charles-Etienne; GRAVELOT, Hubert F.; COCHIN, Charles N., 1791, vol. 1, p. 87. 
Christian Art, Dept. of Art and Archaeology, Princeton University in association with Princeton University Press, 2000.

HUGO DE SAN VÍCTOR, Summa Sententiarum, (en MIG$\mathrm{NE}, \mathrm{PL}$ 176).

IMPERIAL, Francisco de, El dezir a las syete virtudes y otros poemas, Madrid: Espasa-Calpe, 1977.

LEÓN COLOMA, Miguel Ángel, "Iconografía de la Prudencia en España durante los siglos XV y XVI", Cuadernos de arte de la Universidad de Granada, 1989, 20, pp. 65-78.

MACROBIO, Comentario al "Sueño de Escipión" de Cicerón, Madrid: Gredos, 2006 (Traducción de Fernando Navarro Antolín).

MACROBIO, Saturnales, Madrid: Akal, 2009 (Traducción de Juan Francisco Mesa Sanz).

MÂLE, Émile, L'Art religieux de la fin du XVle siècle du $X V I l e$ siècle et du XVIIle siècle ètude sur l'iconographie après le concile de Trente. Italie, France, Espagne, Flandres, París: Armand Collin, 1951.

MATEO PALACIOS, Ana (ed.), Flor de Virtudes, Zaragoza: Prensas de la Universidad de Zaragoza, 2013.

MAUPEU, Philippe, "Les aventures de Prudence, personnage allégorique, Ve-XVe siècle". En: BERRIOT-SALVATORE, E., La vertu de prudence: entre Moyen Âge et âge classique, París: Classiques Garnier, 2012, pp. 33-53.

McGUIRE, Thérèse B., "Psychomachia: A Battle of the Virtues and Vices in Herrad of Landsberg's Miniatures", Fifteenth-Century Studies, 1990, 16, pp. 189-197.

MENA, Juan de, "Coplas que fizo el famoso Juan de Mena contra los pecados mortales". En: Cancionero castellano del siglo XV, Madrid: Bailly Bailliére, 1912.

MENDO, Andrés, Príncipe perfecto y ministros aivstados, Lyon: Horacio Boissat y George Remevs, 1662.

MONTESINOS, María, "Los fundamentos de la visualidad de la Prudencia", Imago: revista de emblemática y cultura visual, 2014, 6, pp. 97-114.

MONTESINOS, María, "No hay Fortuna sin Prudencia". En: GARCÍA MAHÍQUES, R.; DOMÉNECH GARCÍA, S. (eds.), Valor discursivo del cuerpo en el barroco hispánico, València: Universitat de València, 2015, pp. 113-120.

MONTESINOS, María, "El tiempo en la visualidad de la Prudencia". En: BALLESTER, B., BERNAT, A.; CULL, J. (eds.), Encrucijada de la palabra y la imagen simbólicas, Palma de Mallorca: José J. de Olañeta, 2017, pp. 505-516.

PASTOR, Luis G., Iconología o Tratado de alegorías y emblemas, México: Imprenta Económica, 1866.
PIERGUIDI, Stefano, "'L'Allegoria della Prudenza' di Tiziano e il 'Signum Tricipitis' del Cerbero di Serapide", International Journal of the Classical Tradition, 2006, 13, 2, pp. 186-196.

PIZÁN, Cristina de, La rosa y el príncipe: voz poética y voz política en las "Epistolas", Madrid: Gredos, 2005.

PRADAS, Daude de, Four cardinal virtues, Florencia: A. Würtenberger, 1879.

PUTTFARKEN, Thomas, Titian and Tragic Painting. Aristotle's Poetics and te Rise of the Modern Artist, Londres: Yale University Press, 2005.

RAMAN, Shankar, "Performing Allegory: Erwin Panofsky and Titian's 'Allegory of Prudence'", Emblematica, 2003, 13, pp. 1-38.

RAMÍREZ, Santiago; URDANOZ, Teófilo (eds.), Suma Teológica, Madrid: Editorial Católica, 1960, vol. 8 (Traducción de Francisco Barbado Viejo).

RIPA, Cesare, Iconología, Madrid: Akal, 2007.

SAAVEDRA FAJARDO, Diego de, Idea de vn príncipe político christiano, Valencia: Francisco Ciprés, 1675.

SAN AGUSTín, Epistolae, s. IV (en MIGNE, Jean Paul, Patrología latina, 33).

SANTO TOMÁS, Summa Theologica, Madrid: Editorial Católica, 1960 (Traducción de Francisco Barbado Viejo).

SASTRE VÁZQUEZ, Carlos, "Animales virtuosos. A propósito de una nueva interpretación de la Alegoría de Tiziano en la National Gallery de Londres", Espacio, tiempo y forma, 2001, 14, pp. 31-56.

SEBASTIÁN, Santiago, El Fisiólogo. Seguido de El Bestiario toscano, Madrid: Tuero, 1986.

SÉNECA, Epístolas Morales a Lucilio, Madrid: Gredos, 2000 (Traducción de Ismael Roca Meliá).

SENÉS, Gema, "La imagen de la prudencia en los Hieroglyphica de Pierio Valeriano: Loci comunes en la tradición simbólica". En: ZAFRA MOLINA, R.; ARANZA, J. J. (eds.), Emblemática transcedente: hermenéutica de la imagen, iconología del texto, Universidad de Navarra y Sociedad Española de Emblemática, 2011, pp. 759-772.

TUCKER, Shawn, The Virtues and the Vices in the Arts, Cambridge: The Lutterworth Press, 2015.

TUVE, Rosemund, "Notes on the virtues and vices 1: two fifteenth-century lines of dependence on thirteenth and twelfth centuries", Journal of the Warburg and Cortland Institutes, 1963, 26, pp. 264-303.

VIVES-FERRÁNDIZ, Luis, Vanitas: retórica visual de la mirada, Madrid: Encuentro, 2011

ZAFRA MOLINA, Rafael, "El prudente Tiziano y su emblema de la prudencia", Potestas: Religión, poder y monarquía, 2010, 3, pp. 123-146. 